\title{
Al bello aparecer de este lucero. Metatextualidad poética en la escritura de Fernando de Herrera y Enrique Lihn
}

\author{
Al bello aparecer de este lucero. \\ Poetic meta-textuality in the works of Fernando de Herrera and Enrique Lihn
}

\author{
Ana María Riveros Soto
}

Pontificia Universidad Católica de Valparaíso. Correo electrónico: ana.riveros@pucv.cl

\begin{abstract}
El presente artículo busca efectuar un examen conjunto de la obra del poeta español Fernando de Herrera (1534-1597), máximo representante de la Escuela Sevillana y anticipador del espíritu barroco, y del poemario Al bello aparecer de este lucero (1997a [1983]) de Enrique Lihn (1929-1988), en función del análisis de la metatextualidad que subyace en la producción de ambos autores y que permite la configuración de una poética afín, manifestada por medio de la estética manierista-barroca y el dilema amoroso, éste último como clave central a través de la cual se busca dar cuenta de una problemática metadiscursiva asociada a la comprensión crítica del fenómeno poético y a la imposibilidad de su revelación, lo que es representado por una serie de dispositivos simbólicos: el lucero, la amada, la imagen, la belleza, la escritura y la memoria.
\end{abstract}

Palabras clave: metatextualidad, poética, barroco, belleza, memoria, sujeto

The aim of this article is to examine the works of the Spanish poet Fernando de Herrera (15341597), leader of the Sevillian School of poetry and early advancer of the Baroque spirit, and the book of poems Al bello aparecer de este lucero (1997a [1983]) by Enrique Lihn (1929-1988), in order to analyze the underlying meta-textuality in the poetic production of both authors. This meta-textuality enables the configuration of a common form of poetry, displayed through a Mannierist Baroque aesthetic and the dilemma of love. The latter predicament becomes the key through which both authors seek to explain a meta-discourse problem associated to the critical understanding of the poetic phenomenon and the inability to reveal it, thereby representing it through a series of symbolic devices: the daystar, the loved one, the image, the beauty, the writing and the memory.

Keywords: meta-textuality, poetry, Baroque, beauty, memory, subject 


\section{INTRODUCCIÓN}

La primera referencia en torno a la presencia del poeta andaluz del Siglo de Oro, Fernando de Herrera (1534-1597), en la obra de Enrique Lihn (1929-1988), específicamente en el poemario Al bello aparecer de este lucero (1983), la constituye el sintagma adverbial que le otorga a éste su nombre, el que proviene precisamente de un verso herreriano perteneciente al poema Canción, tal como refiere en su estudio Ricardo Yamal (1986: 110)․ A partir de esta mención en el título y de otras huellas presentes en la obra de Lihn, analizamos a continuación los referentes metatextuales configurados por el autor en diálogo con la escritura de Herrera, ésta última bajo la comprensión de una poesía surgida en periodo de transición, en el seno de una edad en crisis - fines del siglo XVI - y, por ende, determinada por el desplazamiento de una concepción de la lírica que transita desde los dominios de la corriente renacentista hacia contextos cargados de tensión retórica, entendidos posteriormente como manierismo y barroco (Carilla 1983: 22-23). En esta línea, Foxley (1995: 276) sostiene que en la poesía de Herrera se manifiesta una relevante carga de hibridez al recoger conjuntamente tradiciones provenientes de las tendencias clásicas y medievales, por un lado, y el cuestionamiento del espíritu idealista y renacentista, por otro. De este modo, el trance amoroso en Herrera da cuenta del periodo crítico y conflictivo que marca la transición entre Renacimiento y Barroco, como reflejo de la problemática en torno a los valores y la desorientación de la edad contrarreformista (Macrí 1959: 26). La imposibilidad del anhelo amoroso en el contexto de la expresión manierista y barroca que se anticipa, constituye entonces el primer punto de articulación entre la poesía de Fernando de Herrera y Enrique Lihn, a partir de lo cual se manifiestan diversos aspectos provenientes de una misma problemática metapoética subyacente en ambas obras. Precisamente, en torno a las relaciones entre amor y escritura presentes en Lihn, Foxley señala:

La escritura de Lihn, como lo hace el amor, se abre a compartir con otros, a formar parte de un horizonte común. Es una ocasión para un reconocimiento mutuo, pero también para el desasimiento en el ámbito de un trabajo o una relación problemática, que implican a la vez un desafío y un conflicto, los que a su vez reproducen las condiciones conflictivas de la sociedad. (1995: 275-276).

Tal relación problemática, tanto en el amor como en la escritura, es referida igualmente por Yamal, quien asume esta última como un espacio de ficcionalización y disociación del yo a raíz del dilema amoroso que sitúa al amante en los terrenos fluctuantes del amor, la ilusión, el escepticismo y la ironía. Esta "lucha imposible de resolver" (1986: 119), en palabras del autor, se funda precisamente en la imposibilidad del sujeto para alcanzar la felicidad mediante la concreción de la

La poesía de Fernando de Herrera ha sido recogida en distintas ediciones y estudios principalmente españoles. En la edición utilizada por Yamal, correspondiente al texto Poesías de Fernando de Herrera, con prólogo y notas de Vicente García de Diego (Madrid: Ediciones de La Lectura, 1914), el poema que consigna el verso citado es publicado bajo el nombre de Canción V (1914: 171-178), al igual que en la reedición efectuada en 1963 por EspasaCalpe (1963: 118-124). Por su parte, en la antología recogida por Oreste Macrí, en su estudio denominado Fernando de Herrera (1959), el verso es constitutivo del poema II de la sección Canciones (1959: 451-454), mientras que en la edición de López Bueno el mismo texto poético recibe el nombre de Canción IIII (Herrera 1998: 307-313). 
pasión amorosa (1986: 113), asunto que se inscribe en la poesía de Lihn a través de las claves que provee el intertexto herreriano. Por medio del presente estudio, no obstante, proponemos abordar este componente en razón esencialmente de su carácter metatextual en tanto en ambos poetas, postulamos, el conflicto se asocia a la comprensión crítica del fenómeno poético y a la imposibilidad de su revelación, problemática frente a la cual el amor constituye un dispositivo simbólico cardinal en torno al cual se configuran otros agentes - la amada, el lucero, la belleza, la imagen, la escritura y la memoria - que, en su conjunto, relación y totalidad, son igualmente subsidiarios al conflicto de orden metapoético que sustentan ambas escrituras ${ }^{2}$.

\section{Metalengua y metateXtualidad literaria}

Mignolo define el fenómeno metadiscursivo como "un principio o método de interpretación" (1978: 248) que constituye la base del proceso de escritura por parte de un autor, y cuyo resultado se proyecta internamente sobre ciertas estructuras conceptuales que se expresan en la metalengua $(\mathrm{Mg})$, constituida ésta específicamente por un sistema de creencias (SC) - estéticas y conceptuales-, un conjunto de técnicas (CT) y la racionalidad (Ra) de ambos aspectos (Mignolo 1978: 248-249). Lo anterior corresponde al proceso de semiotización, basado en la transformación de las estructuras verbales del sistema primario, es decir, las lenguas naturales, en estructuras verbo-simbólicas del sistema de modelización secundario, entre ellas, el arte (Lotman 1982: 20). Lo literario constituye entonces una parcela del subconjunto texto delimitado por la metalengua, categoría mediante la cual se conceptualizan diversas interpretaciones respecto de lo que entendemos por literatura, de acuerdo a la función y valor que les atribuye la matriz socio-cultural a la cual éstas pertenecen (Mignolo 1978: 57-58). Iván Carrasco señala que la metalengua corresponde a este "principio o método de interpretación de la literatura total o parcial de un autor determinado, que debe ser reconstruido a partir de las informaciones dispersas de los escritores que la producen o asumen y de los textos que la manifiestan" (Carrasco 2001: 11). El autor sostiene que las metalenguas pueden manifestarse en el texto de manera explícita - es el caso de manifiestos o poéticas - o bien implícita, como sucede en la poesía de Herrera y parcialmente en la de Lihn, en torno a cuya dimensión metatextual la crítica ha hecho amplia referencia (Llanos 1995; Espinoza 2000; Polanco 2004; Valdés 2008; Galindo 2002)3.

\footnotetext{
Si bien, coincidimos con Yamal (1986) en el abordaje de algunas claves poéticas herrerianas presentes en Lihn, entre ellas, la evocación a la amada ausente, el espíritu contradictorio propio del barroco, la fluctuación constante entre amor y desamor, la presencia de un sujeto débil y fantasmal, y otros motivos como son el laberinto y la memoria; estos elementos analizados por el autor en función de su carácter intertextual, constituyen bajo nuestra lectura referencias desde las cuales se simboliza y representa el sentido metatextual de las poéticas de Fernando de Herrera y Enrique Lihn, basado en la imposibilidad que implica la revelación del fenómeno poético, eje central del presente trabajo.
}

\footnotetext{
Respecto al carácter metatextual de la poesía de Lihn, Galindo (2002) se ha referido al sentido crítico-reflexivo que se plasma en su escritura, en función del permanente poner a prueba los mecanismos por medio de los cuales se construye el arte y, por ende, de la desconfianza ante las posibilidades que ofrece la palabra poética.
} 


\section{PoÉTICA, CRISIS Y REPRESENTACIÓN}

Fernando de Herrera es reconocido por la crítica (López Bueno 1987: 54) como el autor del más relevante y único tratado de arte poética del siglo XVI: las Anotaciones de Fernando de Herrera a las Obras de Garcilaso de la Vega (Sevilla, 1580) en las cuales, además del prolijo examen efectuado en torno a la producción de este último, se plasman una serie de principios estéticos que marcaron el paso del periodo renacentista — Garcilaso - al barroco de Góngora (López Bueno 1987: 35). En este marco, Herrera no desecha el material proveniente del clasicismo de acuerdo a su afán cultista, como tampoco defiende su uso en base a la continua apropiación y repetición sistemática de temas y formas italianas practicadas por los petrarquistas españoles; sino que, por el contrario, propone a partir de él una búsqueda de nuevas ideas y formas de belleza, basadas en la imaginación y el intelecto (Macrí 1959: 93). De este modo, el poeta introduce en su obra una serie de recursos que hacen que la mesurada estética petrarquista derive en una poesía culta e intrincada, abundante en artificios propios del espíritu barroco que anticipa, entre ellos, el enriquecimiento idiomático, una mayor complejidad sintáctica, el énfasis retórico, la multiplicación de los cultismos latinos, el uso de la grandilocuencia y la suntuosidad (Alborg 1970: 842). En esta línea, la producción herreriana se funda, conforme a su poética, en las teorías de la imitación platónicas que constituyen la base de los preceptos aristotélicos en torno a la noción de mímesis a través de lo cual el poeta toma conciencia del lenguaje como instrumento esencial de la poesía, esto es el lenguaje entendido como mímesis, como acto de representación "de las cosas por medio de la voz" (Díaz-Plaja 1949: 579). De este modo, Herrera expone en sus Anotaciones:

Así como nace aquella agradable i hermosa belleza, que embelece i ceba los ojos dulcemente, la elección de buenos colores [...] así del considerado encogimiento de vozes imitar las diferencias sustancias de las cosas, procede aquella suave hermosura que suspende i arrebata nuestros ánimos con maravillosa violencia, i no sólo es necesario el escogimiento, sino mucho más la composición. (Cit. en Díaz-Plaja 1949: 579).

Herrera deja de manifiesto el valor representativo del lenguaje poético que, en su fuerza mimética, es capaz de recrear una realidad que será objeto de asombro y admiración, no obstante, es también consciente que aquel deslumbramiento por la belleza de las palabras y su conjugación en la sintaxis no deriva de la evocación exacta o fiel del mundo referencial, sino que por el contrario, éstas solo imitan o reproducen una realidad que, en rigor, está ausente o es inexistente. De este modo, la propuesta herreriana se centra en lograr que tal imitación compuesta por palabras sea lo más bella posible a través del uso recurrente del entendimiento, los cultismos y la retórica; en definitiva, es la poesía entendida como creación de la belleza hecha de palabras, una "belleza intelectiva" (Macrí 1959: 95). Para el poeta, la lengua es concebida como una entidad viviente, dotada de una potente fuerza creadora cuyo fundamento se sitúa siempre en el plano de las ideas y lo intangible, en función de su carácter mimético. Esta misma preocupación tiene lugar igualmente en el campo del arte pictórico, respecto del cual el espectro ilusorio que se conforma en la tela no constituye para Herrera otra cosa que un "engaño" basado en los juegos de luz y de sombra: 
aparece lo fingido en el plano, como si fuesse verdaderamente corporeo i revelado, assi mesmo se conoce tambien por la prospetiva en cualquier cuerpo fingido en el plano la sombra que el pertenece, supuesta la luz de un sitio terminado; i al contrario por la parte umbrosa se conoce lo iluminado. i en los cuerpos redondos de la luz i la sombra tanto mas o menos intensa, cuanto està el luminoso mas o menos opuesto al opaco $[\ldots]$ desta manera es tan grande i maravilloso el engaño de la pintura; estando dispuestas estas cosas en sus proprios lugares de luzes i sombras, escorços i apariencias... (Cit. en Macrí 1959:102).

La ilusión proyectada por la materia verbo-simbólica como también plástica, constituye un aspecto central de la estética herreriana a través de lo cual el instante de revelación poética, generado por la belleza, es situado en el mero plano de las apariencias, lo que acontece a su vez determinado por la posición y disposición del sujeto que observa, en función de la noción de perspectiva, "auténtico engaño de la vista" (Macrí 1959: 101), desde la cual tiene lugar el proceso creador.

Del mismo modo como en la propuesta herreriana se enfatiza el carácter aparente y artificioso de la ilusión poética, en Lihn se manifiesta la precariedad que constituye en sí mismo el ejercicio de escritura, pues la palabra no es otra cosa que un instrumento de representación mediante la cual se encarna la ausencia de acciones y entidades evocadas: "Todo está hecho de palabras [...] son tropos: pavoneos de nada" (Lihn 1997a: 46). En ambos autores, precisamente, se reconoce el carácter efímero e inasible que involucra, en rigor, la voz lírica, lo que conduce al dolorido sentido de imposibilidad que se evidencia respecto al fenómeno poético y, particularmente en Lihn, al cuestionamiento de su propósito, la puesta en crisis en torno al carácter utilitario y al sentido del proceso escritural. Nómez habla, al respecto, de una "poesía de la contradicción", en tanto reconoce en Lihn la presencia de "un conflicto en que se busca la destrucción de la poesía misma, pero muriendo y reviviendo sus propios destellos vitales" (Nómez 1992: 292). En Herrera como en Lihn, tales destellos constituyen proyecciones del lucero que encandila y seduce, en la metáfora del amor, al hablante y lo traslada sin miramiento hacia el dominio del vacío, la desaparición y el desengaño, proceso que busca ser disimulado por medio de la plétora verbal manierista y barroca, a la cual recurre la voz lihneana (Foxley 1995: 276). En ambos autores acontece, en consecuencia, la imagen del amor como metáfora del deslumbramiento, fugacidad y ausencia de un encuentro que no se produce, alegoría de un dilema metapoético que involucra en Lihn la relación entre muerte, silencio y literatura:

La tensión hacia la muerte de la literatura es - lo comprendo muy bien en la letra propia, la de mi propio cuerpo verbal- extrema. [...] Los lenguajes no lingüísticos revelados por la semiología, pueden inducir a la afasia; la despoetización del lenguaje poético, en su pretendida literaturidad, al silencio: no a 'la poesía del silencio' sino al silencio propiamente tal, a secas. (Lihn 1997b: 478-479).

\section{Sujetos DeSLumbrados, CARBOnizados y EXTINGuidos}

El poema de Lihn titulado Fernando de Herrera. 1534-1597 (Lihn 1997a: 26-27), publicado en el poemario de 1983, hace referencia directamente a la figura del 
poeta español, en razón de su obra y de sus antecedentes biográficos, esto último consignado inicialmente por las fechas que acompañan al nombre del poeta en el título: años de su nacimiento y muerte, existencia circunscrita en la transición entre estética renacentista y el posterior barroco. El poema de Lihn alude a la presencia en la vida de Herrera, como "textualidad de base", de doña Leonor de Milán de Córdoba y Aragón, señora de don Álvaro Colón y Portugal, biznieto del descubridor y segundo conde de Gelves, quien en 1559 fijó su residencia en Sevilla y en cuyo palacio, a orillas del Guadalquivir, solía recibir a una amplia corte de escritores sevillanos, entre los cuales se encontraba el poeta español. La condesa constituye, precisamente, para Herrera el motor y objeto de su creación poética, pues gran parte de su lírica gira en torno a su figura (Yamal 1986: 110), a quien transformó en sus textos nominalmente bajo los apelativos de Luz, Luzero, Estrella, Lumbre, Sol, Eliodora, entre otros, y a partir de los cuales emerge la imagen de "éter luminoso" que desrealiza, no obstante, la figura del sujeto amado cual huidiza aparición. Del estado civil de doña Leonor y su desdén ${ }^{5}$, derivan las precarias esperanzas del poeta y, por ende, la imposibilidad del amor, tópico que determina toda su poesía amorosa. De acuerdo a ello, en Lihn comparecen las marcas de un sujeto herreriano que sólo sobrevive en la congoja por la ausencia y no correspondencia de su amada quien, como apunta el mismo poeta sevillano, "i s'olvida de quien cuidoso de su afán la llama" (Cit. en Macrí 1959: 438), dando paso a la imposibilidad de la felicidad en el cumplimiento del anhelo amoroso (Yamal 1986: 113) y a la inminente desaparición del objeto de su deseo, lo que concluye, en consecuencia, con la imagen en el poema lihneano de un Herrera transfigurado en "mariposa viva y carbonizada":

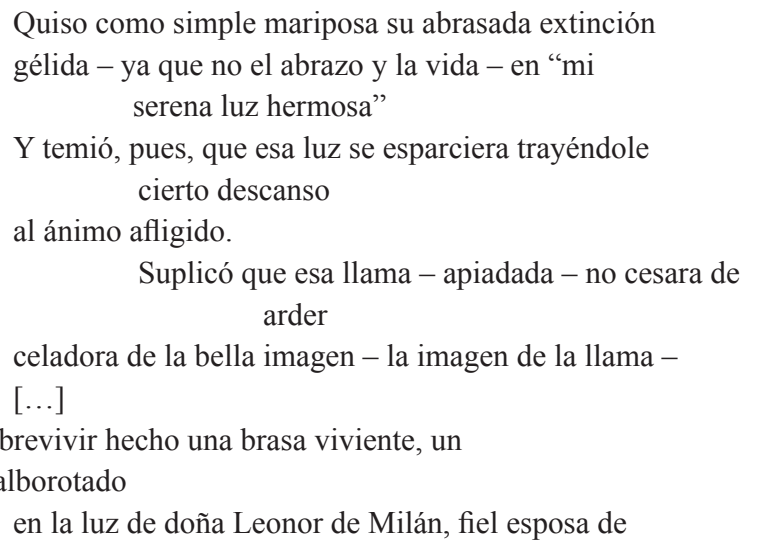

\footnotetext{
En Conversaciones con Enrique Lihn (1990) de Pedro Lastra, se alude a este concepto en relación a los datos autobiográficos sobre los cuales se articula, en ciertos casos, la obra literaria: "E. LIHN: (...) El sujeto que escribe debería tener siempre una conciencia de que es 'literatura', puesto que se emplaza en el presente del texto: tiempo de la escritura, no un tiempo existencial. Desde allí juega con todas las oportunidades que le ofrece el lenguaje para producir efectos análogos a los que la realidad ha producido en el autor real. / P.LASTRA: Es decir, también hay una función intertextual, en la que la experiencia pasa a ser una textualidad de base de esa otra textualidad que es la literatura. Parafraseando a Sollers se podría decir que las instancias biográficas están inscritas allí, en rigor se habrían estructurado en el texto escrito "como diferencias"” (Lastra 1990: 106-107).
}

5 Macrí apunta que el desdén, como constante fija de la lírica de Herrera, constituye un tópico del petrarquismo renacentista y, a su vez, un elemento propio del "desesperado heroísmo barroco" (Macrí 1959: 43). 


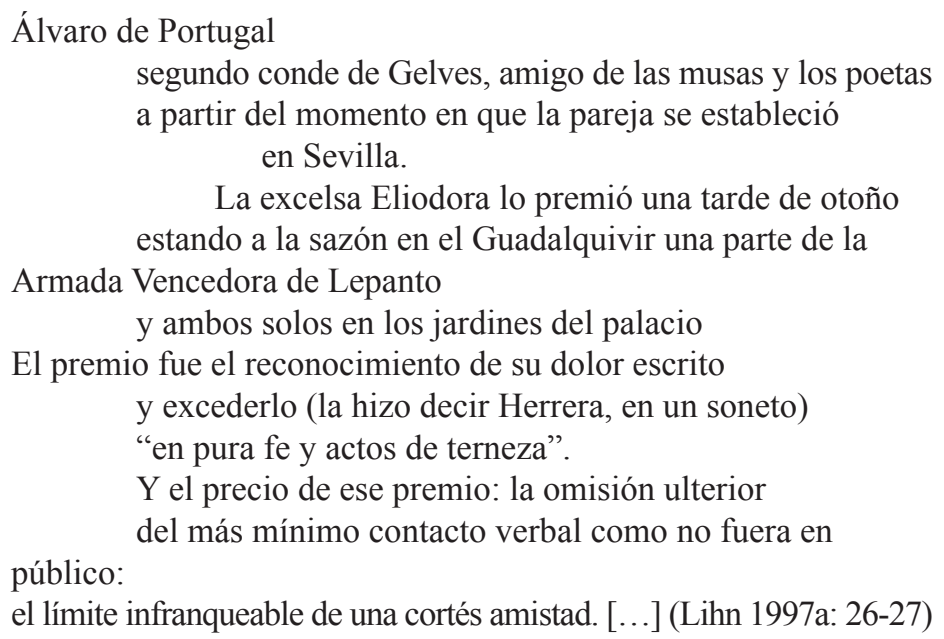

En Lihn, el texto hace referencia a la llama de una pasión amorosa determinada por la imposibilidad de su concreción y consumación, por tanto, condenada a muerte, a la extinción a la cual conduce el mismo fuego que, junto con el desamor, constituyen una "abrasada extinción gélida" (Lihn 1997a: 26), a propósito del ardor y aflicción inmediata que produce el sentimiento no correspondido, lo que se evidencia no solo mediante el contraste abrasada/gélida, propio de la estética barroca, sino también en función del cruce semántico que asume inherentemente cada componente del oxímoron, en tanto uno es constitutivo del otro: la brasa contiene el hielo, el amor comprende necesariamente el dolor. Amor y desamor constituyen una misma y sola fuente para el fuego, el hielo, la llama y su extinción, motivo por el cual tanto el hielo como el fuego pasional queman e incineran permanentemente al amante, una y otra vez, cual Sísifo en su agonía, tal como se evidencia en los versos herrerianos: "Amor; con que me hieres aporfía, / blanco tu ardiente fuego i frío ielo. / Mas que puedo esperar d'esta blancura; / pues tiene 'n blanca nieve 'l pecho tierno / Contra mi fiera llama defendido? [...] qu'abrasado en vigor de fuego eterno / muero en un blanco ielo convertido" (Cit. en Macrí 1959: 430).

Dicha extinción lleva a negar, tanto en Herrera como en Lihn, no solo la posibilidad del deseo amoroso en el sujeto, sino también su propia existencia como entidad que ama: "muero en un blanco ielo convertido" (Cit. en Macrí 1959: 430); "Quiso como simple mariposa su abrasada extinción / gélida [...] Quiso sobrevivir hecho una brasa viviente, un / cadáver alborotado" (Lihn 1997a: 26). Las brasas calcinan y aniquilan aquello que a su vez la hacen surgir, el amor, y asolan, por consiguiente, la propia existencia del amante: "-ya que no el abrazo y la vida-" (Lihn 1997a: 26). La sobrevivencia constituye entonces la única posibilidad para ser y existir, no obstante, como "mariposa viva y carbonizada" (Lihn 1997a: 26) a la cual ya volar y huir le es imposible. El amante persiste entonces en medio de su agonía entre el deseo de la vida y la muerte, entre pasión y desafecto, movimiento pendular de quien teme y desea, a su vez, su propia muerte y salvación: "Y temió, pues, que esa luz se esparciera trayéndole / cierto descanso / al ánimo afligido [...] la luz de doña Leonor de Milán” (Lihn 1997a: 26). Esta misma ambivalencia se reconoce en los sonetos de 
Herrera: "i en llama ingrata ufano me consumo / [...] que solo de m' incendio resta el humo" (Cit. en Macrí 1959: 426), “Cessa Aura, no m’enciendas mas; qu'en ella / ardo siempre, i me abráso en llama pura / ah no añadas mas fuego a mis ardores" (Herrera 1998: 268); como al mismo tiempo se evidencia el miedo a la extinción de la luz -doña Leonor-y, en consecuencia, a su desaparición en la penumbra que constituye en sí mismo el propio sujeto: "Buelve tu luz a mi, buelve tus ojos; / antes que quéde oscuro en ciega niebla” (Herrera 1998: 207); aflicción ante la cual el poeta amante suplica para que "esa llama - apiadada - no cesara de / arder / celadora de la bella imagen - la imagen de la llama -" (Lihn 1997a: 26).

La imagen que constituyen el fuego y la llama corresponde, en ambos autores, a la nítida y pura representación del objeto amado como también del deseo amoroso que a partir de él surge, en tanto ambos son irreales, imposibles de alcanzar y materializar. Sin embargo, tanto en Lihn como en Herrera no es bella la llama ni lo es su luz, sino que es la imagen de la luz, la imagen de la llama la portadora de belleza; es su retrato y no su referente el que deslumbra al sujeto, la proyección o el simulacro de una amada que pierde su realidad - como versa Robert Desnos-y se transforma en "la otra versión"6, aparente e ilusoria de aquello que no existe. El amante no vislumbra entonces a la amada real, sino a aquella imaginada, transformada en el destello de una luz ausente, producto de un ferviente anhelo que, en rigor, remite a un amor irreal, ergo vacío, carente de todo sustento. Tal irrealidad se proyecta, por ende, hacia el mismo amante quien pierde esta condición al desvanecerse el carácter certero del objeto de deseo: amo, luego existo parece ser la premisa que en él se deshace o se invierte en su negativo, despojando de toda realidad al yo que padece el sentimiento amoroso ${ }^{7}$.

La noción de sujeto reviste, precisamente, ciertas acepciones que aluden al carácter inconsistente del mismo. Souriau (1998: 1013) reconoce en torno al término - proveniente del latín subjetus cuyo significado es "situado debajo"- sentidos asociados a la idea de "substrato", mientras que Ferrater Mora (1991: 3416) hace referencia al sentido gnoseológico del mismo, según el cual la idea de lo "subjetivo" remite a aquello dispuesto al interior del sujeto cognoscente, en su mente, lo que en consecuencia no es concebido como real (Ferrater Mora 1991: 3393). Hume sostiene, por su parte, que todo lo que es exterior al sujeto no es cognoscible en sí mismo, por tanto, el objeto no corresponde a otra cosa que a las impresiones y representaciones con las cuales el sujeto construye su conocimiento (Cit. en Giner, Lamo de Espinosa y Torres 2004: 539). De este modo, tanto en Herrera como en Lihn la amada se desdibuja en los retazos de la memoria de un amante, cuya existencia se diluye igualmente a partir de la irrealidad y fugacidad de la luz que anhela, transformándolo por correlación en una entidad frágil, agónica y sombría como se plasma en los

\footnotetext{
En relación a la ausencia, Pedro Lastra en su poema "La otra versión" — publicado por primera vez en Noticias del extranjero (1959-1998) en 1998 - cita el verso de Robert Desnos: "tanto soñé contigo que pierdes tu realidad". En su primera estrofa, el poema de Lastra enuncia: "La otra versión es la que escribo en sueños, / una voz que la letra retiene / repitiéndola / como una línea de Robert Desnos: / tanto soñé contigo que pierdes tu realidad" (Lastra 2016: 59), (la cursiva es de Lastra). Precisamente, a propósito de estos versos y de la desaparición del sujeto amado, Daneri apunta: "El texto sugiere además que escribir y soñar son operaciones equivalentes cuyo constante empeño no necesariamente acerca al sujeto a su objeto sino, muy por el contrario, lo disuelve" (Daneri 2005: 46).
}

7 En el poema "Tanto soñé contigo" de Robert Desnos se lee: "Tanto soñé contigo, tanto caminé, hablé, me tendí al lado de / tu fantasma que ya no me resta sino ser fantasma entre / los fantasmas [...]" (Cit. en Pellegrini 1961: 130). 
siguientes versos herrerianos: "buelve y revuelve 'l simple devaneo; / i lleva por despojos / fuego en el coraçon, llanto en los ojos." (Cit. en Macrí 1959: 450); "voi, como sombra palida," (Cit. en Macrí 1959: 437); "en esta sombra ven con faz serena" (Cit. en Macrí 1959: 432); “yo muero al fin perdido" (Cit. en Macrí 1959: 437). "i lloro ausente i solo aquella Lumbre" (Cit. en Macrí 1959: 465). Por su parte, el carácter inconsistente del sujeto, ausente y falto de toda materialidad, se reproduce en Lihn a lo largo del poemario producto de la sujeción — subjetus - del amante a una entidad ilusoria y, por ende, causante de su propia irrealidad: “¿guardas aún mi sombra de recuerdo? / El mensajero de la nada soy / y la ferocidad de un pobre diablo" (Lihn 1997a: 52); "Que ausencia, querida, ocupé en mi presencia / desfasado, en realidad, de la trama / de la que tú eras la historia central" (Lihn 1997a: 53); "He muerto para ti” (Lihn 1997a: 55); “Así me dejas, en la irrealidad” (Lihn 1997a: 92). En el contexto posmoderno, precisamente, las fronteras que distinguen objeto y sujeto se deshacen (Jameson 2002: 79) en tanto el primero es proyección del segundo. La distancia entre ambos polos se diluye y con ello la figura de sujeto, entidad malograda, escindida e inestable, que se deshace como efecto y causa de la desaparición del objeto amado.

En torno a Lihn, la crítica (Foxley 1995; Galindo 2002; Polanco 2004; Ostria 2005) ha postulado la noción de un sujeto poético como entidad inconclusa, fracturada y descentrada: "Una figura heterogénea que borronea los rasgos de su identidad. La imagen de un sujeto disgregado en rasgos fragmentarios que no alcanzan a construir una identidad unitaria, sí una apariencia híbrida, mestiza" (Foxley 1995: 290). Tal fragilidad se manifiesta a su vez en el deseo del yo por transmutarse en otro que no padezca de desamor, tal como acontece también en Herrera conforme la evocación renacentista del beatus ille: "Dichoso aquel a quien jamás inflama / vano amor, ambición" (1963: 208-209). Lo anterior en Lihn tiene lugar, no obstante, bajo la referencia a un sujeto en condición permanente de irrealidad y simulacro: "Suplantar a una persona por otra; crimen que don Amor quiere legalizar" (Lihn 1997a: 21), "En mi sueño de transformista despierto convertido en ti" (Lihn 1997a: 73). La desarticulación del sujeto se condice a su vez con la aparición ilusoria e insustancial de la amada; ausencia y vacuidad que es revelada con claridad en Herrera - "a quien suspira / tu ausencia" (Cit. en Macrí 1959: 432); "Sola, i en alto mar, sin luz alguna" (Cit. en Macrí 1959: 434) — y denunciada descarnadamente en Lihn: "No era siquiera una mujer fatal / bella, sí, pero espuma de oleaje / un simulacro de la Diosa ausente" (Lihn 1997a: 82). "Soy, más bien, la víctima de ese capricho / el floradicto que aspira de tus flores artificiales" (Lihn 1997a: 103).

En ambos poetas, la ausencia de la amada implica la incapacidad de la misma, a su vez, para ser nominada, designada por el amante a través de un nombre único, estable y certero - no fragmentado - , lo que evidencia el vacío identitario y dolorido que ella misma constituye: "tu nombre, tu valor puesto en olvido" (Herrera 1998: 278); "sin nombre, en ciego olvido sepultado" (Herrera 1998: 285); "y tú, Cloris, una flor de cuyo nombre ni yo puedo estar / seguro" (Lihn 1997a: 57). La palabra, como apunta Gadamer (1992: 199) dota de existencia y determina nuestra relación con el mundo en tanto todo encuentro con la realidad es articulado desde el lenguaje. Sin embargo, la incapacidad para nombrar certeramente a la amada y asirla a través del verbo da cuenta, en Lihn, del carácter crítico de la lengua poética, dominio incierto en el cual tiene lugar el (des)encuentro de dos entidades aparentes, inacabadas — amada y amante-, lo que conduce indefectiblemente a la (no) consagración de un amor 
ilusorio, fundado en la ausencia del referente real designado por la palabra poética: "remedo de algunas escenas que habríamos podido / vivir juntos si todavía fuéramos reales” (Lihn 1997a: 35); “Tú y yo no somos más que palabras” (Lihn 1997a: 86).

\section{LA MEMORIA: ESPACIO DE LA AUSENCIA E ILUSIÓN}

La irrealidad del sujeto y su amada da paso a la configuración de entidades ilusorias que se albergan en los dominios de la memoria, en tanto sus posibilidades de materialización en ella se dibujan y desdibujan a la vez a partir de la fugacidad de la luz o de la "imagen de la llama" (Lihn 1997a: 26), relegando el deseo al espacio de las ideas, lo imaginario, más aún cuando en el aparente contraste el amante es objeto de olvido, tal como se manifiesta en Herrera: "que breve es l'alegría / que tiene algún lugar en mi memoria" (1963: 61), "memoria amarga de mi gloria ausente" (Cit. en Macrí 1959: 449). Considerando los lineamientos platónicos presentes en la estética herreriana, Platón concibe precisamente la memoria como un fenómeno basado en la retención de impresiones y percepciones por parte del sujeto, un "recordar sensible" determinado por el alma que otorga a éste un carácter inteligible (Ferrater Mora 1991: 2357). Para Todorov, a su vez, no es posible restablecer el pasado íntegramente, por lo que la memoria reconstruye la imagen del mismo sobre la base de una selección -olvido y conservación- (2013: 5), cuyo sentido es atribuido por el sujeto que rememora.

En Herrera, la memoria constituye un lugar escindido, dividido en el afán por evocar la luz — imagen, reflejo de la amada - y, a la vez por sumirla en el olvido, gozo y tormento que implica la problemática del recuerdo y de la ausencia/presencia del objeto amado: “Lento y pesado Olvido, que d'el daño / eres, que mas m'aquexa, mayor parte; / si a mi memoria ocupas esta parte" (Cit. en Macrí 1959: 426-427). Olvido o desmemoria definen a una amada que ciertamente no recuerda, falta de juicio que la diluye en su identidad, haciéndola desaparecer como tal y situándola inevitablemente en el plano de lo incierto tal como se propone en los versos herrerianos: "Mas ó, qu'el cielo causa mi gemido; por onrar gente, indina de memoria; / q'uel Sol con tibio rayo apena enciende [...] En este engaño siempre và, i s'olvida / de quien cuidoso de su afan la llama" (Cit. en Macrí 1959: 438). Lo anterior, a pesar de la infructuosa esperanza del amante por sobrevivir en medio del desmoronamiento de la memoria de la amada - dimensión doblemente ilusoria-y, en consecuencia, del desplome del propio yo: "Si la fê te renueva la memoria; / en esta sombra ven con faz serena" (Cit. en Macrí 1959: 432). Tal empresa y el rescate que intenta efectuar el sujeto a través de la memoria se deshace, por consiguiente, en Herrera, en función del carácter incorpóreo del gesto memorístico, fuente profusa para el advenimiento irreal de encuentros y desencuentros entre el yo y la amada.

En Lihn, la memoria constituye, como arguye la crítica (Yamal 1986; Foxley 1995; Ayala 2008; Valdés 2008), un componente relevante de su poética en cuanto este espacio se yergue como uno de los reductos desde el cual el sujeto en crisis intenta sostenerse, reconstruirse a sí mismo y pervivir, en tanto "lo único que persiste es la memoria" (Yamal 1986: 118). Recuerdo, luego existo es en este caso la sentencia por medio de la cual la memoria revela su carácter sobreviviente, la que junto al amor constituyen la última llama o imagen — espejismo - que ruega el amante no 
cese de arder, aun cuando se es consciente del carácter insustancial de su empresa memorística y amorosa: "Cientos, cientos de veces te encontraré a la vuelta / de la memoria abundante en esquinas / en la enrarecida atmósfera del país de los sueños / en que no hay cosa que no esté hecha de nada" (Lihn 1997a: 35); "Tú no eres mi recuerdo de ti / Tu recuerdo es tu aparición de cada día / pero hecha de nada" (Lihn 1997a: 66). Amor y memoria constituyen entonces una misma dimensión a partir de la cual se configura el sujeto amante y, por extensión, la imagen de la amada — “imagen perfecta" (Lihn 1997a: 81)—; dimensión efímera e incorpórea que condena a los sujetos a la inexistencia por medio, a su vez, de la misma escritura poética, en tanto ésta también remite al espacio de la ilusión: "son tropos: pavoneos de nada" (Lihn 1997a: 46), estampas de un "trabajo imaginario" (Lihn 1997a: 53). La imbricación entre memoria e imaginación constituye, precisamente, un problema cuyos antecedentes provienen del mundo clásico, señala Ricoeur, bajo cuya vertiente platónica se sostiene la noción de eikón, esto es la representación de una cosa ausente a partir del engaño articulado por el lenguaje, el sofisma en el cual tiene lugar "la aporía de la presencia de la ausencia" (2000: 26). En este marco, el acto de rememoración constituye un reconocimiento de la impronta o huella - ausencia presente - que da cabida a la falsedad o al error, más aún cuando lo rememorado responde al carácter de simulacro o phantasma - fantasía, irrealidad - en los términos platónicos. La noción de imagen es, por tanto, para Platón un segundo objeto - heteron- correspondiente a una copia símil de lo verdadero (Cit. en Ricouer 2000: 28), en consecuencia, irreal, una mera semejanza - eikõna - ; problemática que dice relación, en definitiva, con la veracidad de lo evocado por la memoria, cuestionamiento o entredicho que se funda en la ausencia y la deformación subjetiva de su referente.

Tal sospecha permite, en Lihn, concebir el ejercicio memorístico como un acto carente de sentido y realidad, por más que el hablante insista en el recuerdo — “cientos, cientos de veces" (Lihn 1997a: 35)—, situación que da paso a la puesta en duda de la autenticidad del referente de toda acción recordatoria, inclusive aquella efectuada por la amada a través de la cual se coloca en cuestión, cual movimiento reflejo, la propia existencia del hablante: “¿En qué piensas que no sea en mí? / ¿En lo real?” (Lihn 1997a: 92). En este sentido, la nada y el vacío constituyen en Lihn el verdadero dominio de la memoria y de la pasión amorosa, el espacio de la ilusión por medio del cual se desarticula y diluye la figura de la amada y del sujeto, a pesar de los vanos intentos de sobrevida que esgrima el yo: "No era la misma, para mí, la materia / de la reminiscencia / [...] y tú sólo el recuerdo de lo que había sido ese acontecimiento / años atrás" (Lihn 1997a: 33).

\section{LA BELLEZA DE LA IMAGEN Y EL ENGAÑo POÉTICO}

En un inicio, la belleza de la amada — germen del sentimiento amoroso - pareciera constituir, tanto en Herrera como en Lihn, el referente auténtico y corpóreo en torno al cual el sujeto emprende la conquista amorosa, alcance que sin embargo se diluye en tanto vislumbrar la luz constituye para el amante "la inminencia de una revelación, que no se produce" (Borges 2010: 14), y que es generada por una imagen ,el lucero, cuyo vacío e inconsistencia es puesto en evidencia. Para Borges, el hecho estético constituye la imposibilidad de esa revelación, producto de una imagen poética que en 
palabras de Octavio Paz "se sustenta en sí misma (...) es la revelación de sí mismo que el hombre se hace a sí mismo" (1996: 137). De este modo, la imagen ilusoria y su belleza acontecen determinados por la subjetividad del mismo hablante, quien desde su propia fragilidad percibe y crea al objeto amado. "La imagen de la amada será el producto poético", plantea Yamal (1986: 113), respecto a la labor escritural que se reconoce en el yo lírico, tal como se propone en los versos de Lihn: "No me digas que en algo tú compites conmigo / que tengo la palabra y tienes la belleza" (Lihn 1997a: 101).

La belleza es definida, precisamente, por Souriau como una cualidad sensible, producto de la experiencia a través de la cual tiene lugar la admiración, el asombro y la prolongación de la contemplación, reacciones que en la tradición platónica pueden asociarse a la idea de amor (1998: 186-187). En ambos poetas, la belleza ensalzada proviene de la luz que irradia la amada, por ende, el sentimiento amoroso tiene lugar en el acto contemplativo de este resplandor, el que -como tal-presente/ ausente acompaña, inspira e ilumina al poeta, como bien se expresa en Herrera: "En tus cristales claros la belleza / Océano, yo veo figurada / de mi Luz" (Cit. en Macrí 1959: 472). No obstante, a diferencia de Herrera, el anhelo amoroso adquiere en Lihn una carga erótica ausente en los versos del español, quien más bien canta según los preceptos de la belleza platónica, tal como se enuncia en la misma escritura lihneana: "me ocurre, de otra / manera, lo que a Fernando de Herrera / a quien la imagen del ser querido encendía «en deseo / de gozar la belleza amada»" (Lihn 1997a: 73). La belleza sensual evocada en Lihn intensifica el resplandor que deslumbra al sujeto y, con ello, el dolor por la pérdida, la descarnada revelación basada en la inconsistencia y el artilugio al que es sometido el amante: “¿Cuántas veces tendría un animal que caer / en la misma trampa? Armada por Eros / cubierta por hojas en que se transparenta el resplandor del cebo: la belleza de Filis" (Lihn 1997a: 81). En Herrera, el mismo verso que titula el poemario de Lihn hace referencia a dicho artificio o engaño:

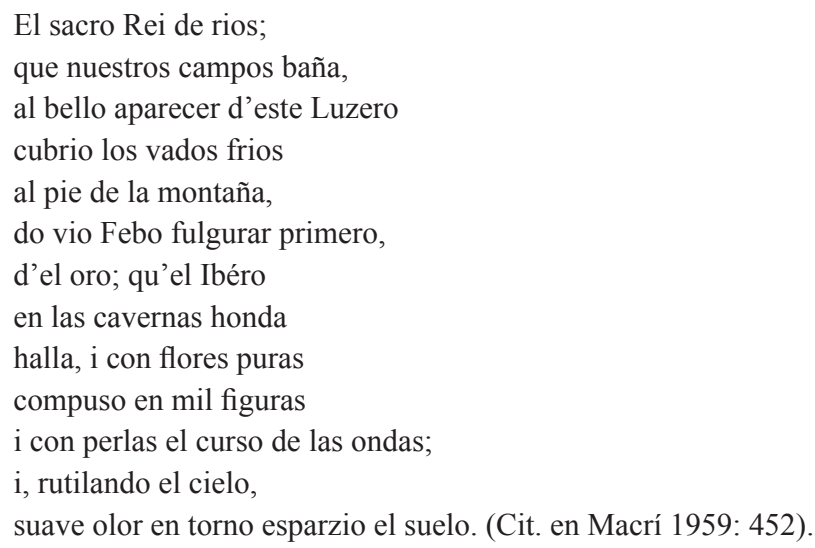

El objeto amado es, tanto en Herrera como en Lihn, el bello aparecer de este lucero que, en el texto herreriano ilumina y transfigura el paisaje regido por el río, cuyas aguas refulgentes y cristalinas, cual espejo, trastocan e invierten la realidad. En Herrera, el amante es conducido por el "bello aparecer d'este Luzero" (Cit. en Macrí 1959: 452) hacia el locus amoenus de la voz renacentista, cuyos campos 
son bañados por el oro y el fulgor que proyecta el río, (des) componiendo "en mil figuras" y apariencias rutilantes este espejismo amoroso. En Lihn, sin embargo, la revelación del engaño transporta al sujeto de golpe al locus horridus, espacio de la memoria en torno al cual expresa "no puedo irme ni quedarme de aquí" (Lihn 1997a: $79)^{8}$; lo anterior, producto del recuerdo y la clara conciencia del yo respecto de la imposibilidad del amor y de la belleza y, en consecuencia, de la poesía misma. Lo bello acontece, entonces, como aquello "que desespera" (Souriau 1998), que provoca, exalta las emociones y crea ilusión a través de "procedimientos de imaginación", según proponen Ogen, Richard y Wood (Cit. en Souriau 1998: 188); es en definitiva, la aparición de una imagen de perfecta belleza, pero "rara e improbable" (Souriau 1998: 187) y, por ende, conducente al fracaso. Paz concibe la imagen poética como "productos imaginarios" (1996: 98), vale decir, como figura real o irreal evocada y/o generada por la imaginación y, por ende, con valoración psicológica por medio de la cual tiene lugar, siguiendo a Otto, el encuentro con "lo Otro" (Cit. en Paz 1996: 129) en base a los sentidos múltiples y contradictorios que provoca: "Asombro, estupefacción, alegría (...) abismo, serpiente, delicia, monstruo bello y atroz” (Paz 1996: 132-133). En ambos poetas, la imagen es entonces simulacro, la ilusión o el engaño visual que reproduce como artificio el arte renacentista y barroco (Baudrillard 2005: 32), recurso que implica, según Eco, el punto de vista subjetivo propio del observador por medio del cual se "«añade» a la exactitud del objeto, la belleza contemplada por el sujeto" (2010: 180). La belleza es, por tanto, una categoría subjetiva determinada por aquello que (se) provoca en el sujeto y que, en Herrera y en Lihn, acontece como un destello instantáneo - bello aparecer-, simulacro de una luz fugaz y ausente que desaparece "en el momento mismo de su aparición" (Lihn 1997a: 16), y cuyo reflejo o imagen da cuenta de una entidad ilusoria, inexistente, un mero evento de la memoria: "Harta irrealidad había ya en todo esto" (Lihn 1997a: 85), "Este es un día hecho, no más, de tu recuerdo" (Lihn 1997a: 66). La aparición/desaparición de la amada, quien es también aparecida, adquiere a su vez en Lihn un carácter espectral o fantasmagórico en tanto su ausencia persigue y perturba la existencia - también aparente- del hablante: "y es tu fantasma el que, además quiero tocar / tu ausencia y tu presencia" (Lihn 1997a: 37), "tú y yo, fantasmas de carne y hueso" (Lihn 1997a: 104).

En los versos herrerianos y lihneanos se descubre al amante en un permanente oscilar entre estados de engaño y desengaño, ilusión y desilusión simultáneos: "Mas cuando hallo mis esperança llena / (...) un subito dolor turba mi gloria, / i todos mis contentos desordena" (Cit. en Macrí 1959: 428), "una Luz se m’ofrece i ardor puro / distante, pero cerca se m'esconde" (Cit. en Macrí 1959: 437), "para el caso es lo mismo; apariciones / y desapariciones instantáneas" (Lihn 1997a: 80). En Herrera, la mención al engaño que provoca la belleza de la $L u z$ es explícita y reiterada, según cuan consciente el sujeto es de aquello: 'Pequeña fue mi gloria, / pero grande l' afán i grande l' daño; / que dexò en la memoria / de belleza desseo, / i dexò a l'alma triste cierto engaño, / qu'en su misera historia / buelve y rebuelve '1 simple devaneo." (Cit. en Macrí 1959: 450); “Qu'el oro, que me tiene en nuevo engaño" (Herrera 1998:

Foxley hace mención a este mismo pasaje, considerando el intertexto de Herrera en Lihn, en el mismo sentido de lo expuesto: "Hay todo un sustrato de experiencias de disimulo y silencio horrendos. Toda esa carga dolorosa late en la palabra y hace del lugar del amor un "lugar horrible". No más un "lugar ameno" propicio para los encuentros, como el de la escena que da título a este libro" (1995: 275). 
235), evocación que a momentos da cuenta de la transmutación del lugar ameno, dada por la conversión de la luz en espantosa oscuridad: "mi alma en un confuso error condena; / i aparece, d'horror medroso llena, / la sañosa aspereza, que lamento" (Cit. en Macrí 1959: 435). Por su parte, en Lihn, el carácter voluble del lucero se manifiesta a través del instante culmine de la pasión amorosa, encuentro que se diluye en el momento mismo de su consumación, goce y pérdida ipso facto de la belleza y el amor: "sobreexcitado por esta transformación que no dura / más de unos segundos pero me desvela" (Lihn 1997a: 73); "En la ciudad más fea de la tierra / se hizo humo a la hora de los quiubos" (Lihn 1997a: 82).

\section{EVOCACIONES BARROCAS: FUGACIDAD Y DUALIDAD}

El contraste, recurso proveniente de las voces manieristas y barrocas presentes en ambas poéticas, da cuenta de la figura del amante en crisis, reflejo y consecuencia de una modernidad implacable que somete al sujeto y determina, en rigor, la condición dual y vacilante de la amada, quien se transfigura en incesantes fragmentos, apariencias y formas opuestas. Tal concidentia oppositorum (Alonso 1970: 348), propia del barroco, se evidencia claramente en Herrera, quien escribe: "viendo en su pura luz nacer mi muerte" (Cit. en Macrí 1959: 450); “Ardió comigo junto en dulce fuego; / i el rigor desató de fria nieve" (Cit. en Macrí 1959: 465); "De que me sirve huir, si mi porfia / contrasta, assegurada de su engaño, / i abraça en el peligro a la esperança?" (Cit. en Macrí 1959: 435). En el poeta sevillano la amada es estrella nocturna y sol de amanecida, dualidad que representa la lógica amor/desamor que articula y desarticula a la vez la existencia — día y noche — del amante: "qu'a alba en calor grande 'l pecho avivo; / i ardo al aparecer d'el nuevo dia / [...] i cuando d'aquel puesto altivo / declina el Sol, me quedo en fuego vivo; y abráso, cuando tuerce al mar la via" (Cit. en Macrí 1959: 439); "Pura, bella, süave Estrella mía, / (...) vestís de luz serena la mañana, / i la tierra encendéis desnuda i fría” (Herrera 1963: 76).

Los sentidos barrocos de fugacidad, ilusión de la vida y fragilidad de la belleza humana (Aguiar e Silva 1975: 287), constituyen también en Lihn el motor de un dolor y desencanto angustioso en el hablante que lo vincula a la muerte — su propia desaparición-, entendida ésta bajo esta corriente como "expresión suprema de la condición efímera" (Aguiar e Silva 1975: 288). En su poesía, el lucero es también estrella, Venus, estrella mayor, y la alegoría de su nacimiento como aparición a la luz de la obra renacentista de Sandro Botticelli, El nacimiento de Venus (1484-1486), en la cual la diosa surge de la espuma de mar como versa el mito de Afrodita, cuyo nombre derivado del griego aphros significa precisamente 'espuma' (Biedermann 2013: 474). En Lihn, Venus es una entidad evanescente, efímera, flotante (Yamal 1986: 111), como también ilusoria y dual, hecho que deviene en la incertidumbre del hablante asociada también a su permanente oscilar: "El bello aparecer de este lucero / ¿El del amanecer? / ¿El de la tarde? / ¿Abre o cierra el día?” (Lihn 1997a: 80), “-Venus, la estrella del amanecer- / y el dolor de la estrella vespertina / la de la otra Venus que agoniza" (Lihn 1997a: 49). El desdoblamiento y vaivén constituyen el rasgo esencial de la luz/amada, carácter pendular que da cuenta de la crisis indefectible a partir de la cual se (des)configura el yo: "un planeta / bautizado de nombres diferentes / al mismo tiempo, pues, errante y fija" [...] en lugar de una estrella veo dos: / luz del 
amanecer luz del crepúsculo / que se distinguen en que son la misma: amor y desamor enamorados" (Lihn 1997a: 49). El fulgor aparente y titilante de Venus — quien en la tradición recibe también el nombre de Phosphoros o Lucifer en tanto portadora de luz (Biedermann 2013: 474) — se proyecta entonces sobre el amante a quien ciega y encandila, transformándolo cual espejo, en el orden de su inversión: origen y efecto simultáneo del carácter escindido, precario y vacío del amor y del desamor. Amante y amada constituyen, por ende, una sola identidad, simbiosis manifestada por medio de la duplicidad, fragmentación y fragilidad del amor como espejismo de una luz ya extinguida, y el desengaño de su revelación: "La desaparición de este lucero / lo puso ferozmente en evidencia / no era Venus, la estrella vespertina / no era Venus, la estrella matutina / Era una lucecilla intermitente" (Lihn 1997a: 82).

\section{IMPOSIBILIDAD DE LA REVELACIÓN: SUJETO Y PALABRA POÉTICA}

La falta o distancia del referente en el sistema verbo-simbólico constituye la base de la trágica y clara conciencia que en ambos poetas se manifiesta en torno a la ausencia que guarda siempre la palabra y, en particular, la palabra poética en función de su valor autorreferencial y mimético. El carácter irreal e inconsistente que configura al sujeto lírico y a la amada deriva de esta comprensión y constituye en Lihn la representación metatextual del escepticismo y la desconfianza expresada en su escritura frente a la palabra poética, referida ya por el mismo autor (Lihn 1969) y la crítica (Pacheco 1988; Polanco 2001; Galindo 2002). El sujeto en la escritura lihneana como entidad verbal precaria, balbuceante y agonizante (Foxley 1995; Espinoza 2000; Polanco 2001) corroboran tal concepción.

Esta reflexión metatextual es, por su parte, manifestada en Herrera por medio de la referencia explícita a su canto poético, recurso concordante con las formas renacentista y barroca de la época y a través del cual el hablante es consciente de la fragilidad y precariedad de su propia voz: "Mas pues que la rudeza / d'este m'indino canto / qu'un desseo simple y llano, / no puede a su belleza / dar nombre i gloria" (Cit. en Macrí 1959: 454); "Voz de dolor, i canto de gemido, / i espíritu de miedo, embuelto en ira" (Herrera 1963: 45). Se reconoce en el poeta sevillano el ejercicio consciente de su propia práctica escritural y, por ende, de la comprensión del yo como entidad lingüística que exige su contraparte en el proceso lector: "Que nadie avrà qu', aviendo aquí aportado, / lea mi mal, i con la faz serena / pásse, i no báñe 'l rostro en tierno llanto" (Cit. en Macrí 1959: 444). El sujeto en Lihn, consciente de sí mismo como materia verbal, deplora que tenga lugar también el acto lector, cual amor consumar, de modo que su palabra — como él mismo - no se extinga inconclusa y silenciada: "Soy un imbroglio de maltratado papel / entre las manos de una lectora desatenta / [...] lee en mí / el último capítulo de nuestra historia en común / para que sepas" (Lihn 1997a: 77). El hablante se sabe mera entidad hecha de lenguaje y, por tanto, insustancial e imposible de acontecer fuera del dominio del texto, lo que da cuenta de su vacío indefectible como signo y referente: "Tú y yo no somos más que palabras" (Lihn 1997a: 86); "la nada torrencial [...] (siempre se habla de nada)" (Lihn 1997a: 20). La palabra poética asume, entonces, la misma condición efímera del lucero, lo que se intensifica en la oralidad, en tanto en esta la materialidad fónica se diluye en el acto mismo de enunciación - "El diálogo es un simulacro / hecho 
de palabras recordadas" (Lihn 1997a: 35)—, develando la necesaria artificialidad del ejercicio escritural que intenta infructuosamente impugnar el vacío que implica su grafía: "la escritura, un modo / aunque insuficiente de prolongar el misterio: / la representación del otro por su ausencia / que encarna en la palabra" (Lihn 1997a: 73). El hablante recurre a su vez a la figura inasible de la amada, proyección verboilusoria del sujeto poético, quien busca sostenerse a sí mismo a partir del deseo amoroso: "Único pilar, tú, de esta torre de palabras" (Lihn 1997a: 42). Tal afán se depliega y ejecuta por medio del único dominio posible de abordar, la palabra, y con ello sobreviene la imposibilidad de toda consumación amorosa, encuentro carnal que representa el mero simulacro de la lengua poética: "Quiero tocar tu letra sin bulto con los dedos / acercarme otro poco / a lo imposible que trasunta la letra. [...] Pasa, preciosa, articuladamente / del cuerpo a tu fantasma / y es tu fantasma el que, además, quiero tocar / tu ausencia y tu presencia / atadas por el lazo de la palabra escrita" (Lihn 1997a: 37). La imposibilidad del amor es la imposibilidad metatextual de la revelación poética, en tanto la palabra no puede acceder a su referente como tampoco dar cuenta del mensaje cifrado que guarda el fenómeno poético. "De las palabras se retira el ser”, apunta Lihn (Lihn 1997: 20), dando cuenta de la ausencia y el vacío que deja aquel develamiento que no se produce. La referencia al mito griego de Filomela ${ }^{9}$ (Martin 2005: 182-183; Ovidio 2013: 406-416) constituye también la alegoría del silencio y del canto poético que calla, que se mantiene en mudez: "'ave parlera la que fue niña muda'" (Lihn 1997a: 45); canto del ruiseñor cuyo mensaje no logra emitirse ni comprenderse y que a oídos del amante acontece atrofiado, malogrado, al igual que él mismo y el encuentro con la amada, ave ligera y huidiza, imposible de apresar: "Soy una desgracia que Philomela acepta porque / de allí brota su canto" (Lihn 1997a: 30). Ante la imposibilidad de tal encuentro y revelación, solo queda el disimulo, la apariencia, la luz perecedera de una verdad inasequible, merodeada fugazmente por el discurso amoroso: "en el hablar de nada [...] la dirección del movimiento / reducido, también, a un simulacro. / Tú y yo hablamos del amor" (Lihn 1997a: 20).

El laberinto, en Lihn, representa este merodeo hacia el centro de una verdad cifrada que intenta vanamente ser aprehendida por el discurso amoroso y la palabra poética. De este modo, laberinto, hilo y minotauro son los pilares de un mundo poético que se despliega y cierra en sí mismo, significados que se tejen y destejen en el hilo de Ariadna, y que se reproducen en el cuerpo del amante, la amada y el engaño de su luz: "Ven ahora a tejerme a que te teja / lúcidamente ciegos" (Lihn 1997a: 60). La trampa es tendida por el ovillo y su hilo, palabras que al igual que el lucero cautivan al hablante, pero al mismo tiempo lo llevan de regreso al espacio original de su constitución y desilusión. Es el laberinto, entonces, espacio del encuentro y extravío de sí mismo, su propio tejido, cuerpo textual en el cual confluyen la presencia y la ausencia: "tal vez el monstruoso encuentro conmigo mismo / en el centro del laberinto y a pesar del amor / (que no deja de ser una palabra)" (Lihn 1997a: 79); "Consuélate pensando que no llegaré nunca al centro / del laberinto / y el minotauro, como se sabe, era

En el mito griego, Filomela es forzada por Tereo, esposo de su hermana Procne. Para evitar que Filomela revele el agravio por él cometido, Tereo corta su lengua. Ante ello, Filomela borda un tapiz a través del cual informa a su hermana de lo sucedido, quien producto de la ira mata a Itis, hijo de ella y Tereo, y se lo sirve a éste como guisado. Al descubrir la venganza, Tereo persigue a las hermanas, instante en que él es transformado en abubilla -ave de aspecto guerrero-(Ovidio 2013: 416), Procne en golondrina y Filomela en ruiseñor (Martin 2005: 182). 
yo / y yo, Teseo, el falso salvador de muchachos y muchachas [...] después de ese enfrentamiento confuso [...] / entre el monstruo y yo el monstruo (Lihn 1997a: 94). El centro del laberinto constituye, por ende, el vacío, la nada misma que implica la imposibilidad del amor y de la palabra poética, "tapiz que se deshace" como apunta Yamal (1986: 114) y del cual, sin embargo, no es posible escapar: "Te he perdido, Ariadna, en este laberinto / que agotó tu ovillo, y el monstruo, querida, soy yo" (Lihn 1997a: 105).

La imposible revelación de la palabra poética, cuya verdad o vacío se mantiene oculto (Paz 1996: 13) involucra, a su vez, un acercamiento al dominio de la muerte, tal como enuncia la voz herreriana: "Crecer la sombra, i anular la lumbre" (Cit. en Macrí 1959: 430). La expresión poética en Herrera y, específicamente, la escritura en Lihn, constituyen intentos vanos por sobrevivir a la muerte como representación, en ambos, de los procesos afligentes y críticos a los cuales somete la modernidad, manifestados a través de la ruptura de ideales renacentistas — principios de simetría y armonía - que son desplazados, en los tiempos de Herrera, por las propuestas manieristas y barrocas que posteriormente retoma y resignifica Lihn en el contexto contemporáneo. Dicha realidad subjetiva, compleja y contradictoria desemboca en el profundo cuestionamiento respecto al sentido de la palabra poética, situación que da cuenta de una conciencia metatextual por medio de la cual se evidencia la inutilidad o insuficiencia del acto escritural ante tales quiebres. El escepticismo o descreimiento respecto de la ilusión acontecida y provisoria — una acción efectiva que vence por un instante la temporalidad (Foxley 1995: 25) - deja, sin embargo, su huella en la escritura en tanto constituye en sí misma un acto de representación, de apariencia, un "bello aparecer". De ello se desprende el sentido elegíaco del discurso poético en tanto canta éste (a) la ausencia, la imposibilidad de acceso a tal revelación y, por ende, a sí misma, lo que provoca, no obstante, la incesante búsqueda a través de la escritura y el acto creador: "yo, quien 'al bello aparecer de este lucero' hice de mi / escritura / el rastro de Leonor de Milán. [...] Una pesadilla de amor que me despierta del sueño" (Lihn 1997a: 71).

\section{OBRAS CITADAS}

Aguiar e Silva, Vítor Manuel. 1975. Teoría de la Literatura. Madrid: Gredos.

Alborg, Juan Luis. 1970. Historia de la Literatura Española. Edad Media y Renacimiento. Madrid: Gredos.

Alonso, Dámaso. 1970. Poesía Española. Madrid: Gredos.

Ayala, Matías. 2008. "Mirada, viaje y memoria en Enrique Lihn”. Taller de Letras 42: 9-2.

Baudrillard, Jean. 2005. Cultura y simulacro. Barcelona: Kairós.

Biederman, Hans. 2013. Diccionario de símbolos. Barcelona: Paidós.

Carilla, Emilio. 1983. Manierismo y Barroco en la Literaturas Hispánicas. Madrid: Gredos.

Carrasco, Iván. 2001. "Pluralidad y ambivalencia en la metatextualidad literaria chilena". Estudios Filológicos 36: 9-20. Recuperado de http://www.scielo.cl/scielo.php?script=sci_ arttext\&pid=S0071-17132001003600001

Borges, Jorge Luis. 2010. Obras Completas II (1952-1972). Buenos Aires: Emecé.

Daneri, Juan José. 2005. "Reescritura y tensión utópica en Noticias del extranjero (1959-1998) de Pedro Lastra". Acta Literaria 30: 35-55.

Díaz-Plaja, Guillermo. 1949. Historia General de las Literaturas Hispánicas. Renacimiento y 
Barroco. Tomo III. Barcelona: Barna.

Eco, Umberto. 2010. Historia de la belleza. Barcelona: Debolsillo.

Espinoza, Christian. 2000. 'Diario de muerte' de Enrique Lihn: la escritura sobre la línea de la muerte. Estudios Filológicos 35: 151-166.

Ferrater Mora, José. 1991. Diccionario de Filosofía. Tomo IV. Barcelona: Ariel.

Foxley, Carmen. 1995. Enrique Lihn: Escritura Excéntrica y Modernidad. Santiago: Universitaria.

Gadamer, Hans Georg. 1992. Verdad y Método II. Salamanca: Ediciones Sígueme.

Galindo, Óscar. 2002. "Mutaciones disciplinarias en la poesía de Enrique Lihn". Estudios Filológicos 37: 225-240. Recuperado de http://www.scielo.cl/scielo.php?script=sci arttext \&pid=S0071-17132002003700014

Giner, Salvador, Emilio Lamo de Espinosa, Cristóbal Torres. 2004. Diccionario de Sociología. Madrid: Alianza.

Herrera, Fernando de. 1914. Poesías. Edición y notas de Vicente García de Diego. Madrid: Ediciones de La Lectura.

. 1963. Poesías. Edición y notas de Vicente García de Diego. Madrid: Espasa-Calpe. 1998. Algunas obras. Edición de Begoña López Bueno. Sevilla: Diputación de Sevi1la, Área de Cultura.

Jameson, Fredric. 2002. El giro cultural. Escritos seleccionados sobre el posmodernismo 1983-1998. Buenos Aires: Manantial.

Lastra, Pedro. 1990. Conversaciones con Enrique Lihn. Santiago: Atelier Ediciones. 2016. Poesía Completa. Valparaíso: Editorial UV de la Universidad de Valparaíso.

Lihn, Enrique. 1969. La musiquilla de las pobres esferas. Santiago: Universitaria. . 1997a. Al bello aparecer de este lucero. Santiago: LOM Ediciones. 1997b. El circo en llamas. Santiago: LOM Ediciones.

López Bueno, Begoña. 1987. La poética cultista de Herrera a Góngora (Estudios sobre la poesía barroca andaluza). Sevilla: Alfar.

Lotman, Yuri. 1982. Estructura del Texto Artístico. Madrid: Istmo.

Llanos, Eduardo. 1995. ‘Acerca de Enrique Lihn'. Prólogo. Porque escribí. Santiago: Fondo de Cultura Económica.

Macrí, Oreste. 1959. Fernando de Herrera. Madrid: Gredos.

Martin, René. 2005. Diccionario de Mitología Griega y Romana. Madrid: Espasa Calpe.

Mignolo, Walter. 1978. Elementos para una Teoría del Texto Artístico. Barcelona: Editorial Crítica.

Nómez, Naín. 1992. Poesía Chilena Contemporánea. Breve Antología Crítica. Santiago: Fondo de Cultura Económica. Editorial Andrés Bello.

Ostria, Mauricio. 2005. El espejo roto. Notas sobre la poética de Enrique Lihn. En Noguerol, Francisca. Contra el canto de la goma de borrar: Asedios a Enrique Lihn. Sevilla: Universidad de Sevilla. 105-120.

Ovidio. 2013. Metamorfosis. Madrid: Cátedra.

Pacheco, José Emilio. 1998. "Enrique Lihn: menosprecio y alabanza de la poesía". El Espíritu del Valle 4/5: 51-53.

Paz, Octavio. 1996. El arco y la lira. México: Fondo de Cultura Económica.

Pellegrini, Aldo. 1961. Antología de la poesía surrealista de lengua francesa. Buenos Aires: Compañía General Fabril.

Polanco, Jorge. 2001. “¿Quién escribe? E. Lihn y J. L. M.” En Cyber Humanitatis 18, otoño. Recuperado de http://www2.cyberhumanitatis.uchile.cl/18/tx4.html 2004. La zona muda. Una aproximación filosófica a la poesía de Enrique Lihn. Universidad de Valparaíso. Santiago: RIL Editores.

Ricoeur, Paul. 2000. La memoria, la historia, el olvido. Buenos Aires: Fondo de Cultura Económica. 
Souriau, Etienne. 1998. Diccionario Akal de Estética. Madrid: Akal.

Todorov, Tzvetan. 2013. "Los usos de la memoria". Memoria. Revista sobre Cultura, Democracia y Derechos Humanos 10: 1-17. Dossier. Instituto de Democracia y Derechos Humanos, Pontificia Universidad Católica de Perú.

Valdés, Adriana. 2008. "Enrique Lihn: Santiago, París, Manhattan". Revista Chilena de Literatura $72: 89-113$.

Yamal, Ricardo. 1986. "El diálogo intertextual en 'Al bello aparecer de este lucero', de Enrique Lihn”. Revista Chilena de Literatura 27-28: 109-119. 
